relative to the processing of the achromatic shades could allow more opportunity for interference from the competing word in color naming than in the naming of achromatic shades. A recent study (Dyer, 1970) has indicated that slow color processing relative to word processing increases interference to color naming in the Stroop test. The similar association of reduced interference with faster processing of achromatic shades in the present study lends further support to an inverse relationship existing between attribute-naming interference and the processing rate of the attribute.

Whereas the differences in naming time for chromatic and achromatic rectangles are small and only barely significant, the difference between achromatic and color versions of the test in the interference condition $(3.8 \mathrm{sec})$ is over 10 times the standard error of this difference. Thus, a barely detectable difference in processing rates for achromatic and chromatic shades by one measure, namely, speed of color naming with rectangular patches, is vastly amplified in the relative attribute-naming speeds with the addition of interference to naming by a competing word. This property of amplifying differences in processing time would appear to make the Stroop test a useful tool for study of the effects of such variables as hue, saturation, and luminance on the rate of peripheral and central processing of color stimuli. Extensions of the Stroop test, such as the present achromatic version, would seem to hold similar potential for study of variables related to the particular attribute being named.

In conclusion, some discussion of the comparability of interference on the chromatic and achromatic versions of the Stroop test is in order. Interference scores were calculated for each $S$ by determining the difference between average naming times for the interference plates and average times for naming with the rectangular patches. Two such average interference scores for all sessions were obtained for each $S$, one for the achromatic and one for the chromatic versions of the test. Interference scores on one version correlated a remarkable .94 with interference scores on the other version. When three $\mathrm{Ss}$ showing extreme interference on both versions of the test were eliminated, the correlation dropped to .71 , which is still a very strong relationship. This indicates that, for purposes of assessing interference, either test is suitable, since such a high correlation implies high reliability for each. An important consequence of this is that a population which includes color

delectives who cannot easily differentiate the colors of the ordinary Stroop test can be readily compared on their performance by using an achromatic version for the group rather than the usual test.

\title{
REFERENCES
}

DYER, $F$. N. Word reading, color naming and Stroop interference as a function of background brightness. USAMRL Report No. 889, August 17, 1970.

JENSEN, A. R., \& ROHWER, W. D., JR. The Stroop color-word test: A Review. Acta Psychologica, 1966, 25, 36-93.

\section{Errors and latency of response as a function of order of presentation of tactile-visual stimuli in concept identification*}

\author{
AARON WOLFGANG† \\ The Ontario Institute for Studies in Education, Toronto \\ and \\ University of Toronto, Toronto, Canada
}

A task using plastic geometric objects was designed to study concept identification through the tactile sense. The overall results of this study showed that errors and time to solution were similar in classifying visual and tactile information, but response latency was significantly longer in tactile than in visual concept identification. Also, there is some suggestive evidence that visual concept identification was facilitated with practice on a tactual task whereas tactual concept identification was not facilitated by practice on a visual task.

It has been pointed out by the anthropologist Hall (1966) that America is a touchless society. Children are often told by their parents, "You can look, but don't touch," and schools support this idea. The schools, except Montessori, offer very little training in utilizing the tactile sense. As far back as the 1700 s, Berkeley contended that an infant learns a ball is round not by looking at it but by feeling it. Until the child actually handled the ball, the sight of its roundness was meaningless. Touch educated vision.

Most studies and theories in concept identification are based on responses to visual stimuli. In contrast, studies exploring parameters that affect tactile concept identification are almost

* This research was partially supported by the Defense Atomic Support Agency, RMD 1.153 and was done while the author was at the Walter Reed General Hospital and Walter Reed Institute of Research. The author is grateful for the assitance of Miss Juanita Weaver and Daniel Hoeschen. †Requests for reprints should be sent to Aaron Wolfgang, Department of Applied Psychology. The Ontario Institute for Studies in Education, 252 Bloor Street West, Toronto 181 , Ontario, Canada. totally lacking. There have been only a few Es who have attempted to compare learning rates in concept identification using such different sensory modalities as audio-visual (Bulgarella \& Archer, 1962; Haygood, 1965; Lordahl, 1961). The present study extends a prior one by Wolfgang (1969), where visual and tactile concept learning were compared. The overall aim of the present study was to explore transfer effects from visual to tactile and from tactile to visual concept learning. In Berkeley's terms, this experiment attempts to answer the question, "Does touch educate vision more than vision touch?"

\section{METHOD}

All 22 Ss were military duty personnel assigned to Walter Reed Army Medical Center. Their overall mean age was 23.91 years (range: 19-33), and mean education was 12.59 years (range: 11-16).

Ss participated in a 2 by 2 repeated measures design that included two orders of stimulus presentation (visual first, tactile second, or tactile first and visual second) and two modes of stimulus presentation (visual-tactile); there was always one relevant 
Table 1

Mean Errors and Mean Time to Solution as a Function of Order of Presentation of $V$ isual and Tactile Stimuli

Relevant Dimensions and Order

\begin{tabular}{lcccc} 
Means & $\begin{array}{c}\text { Tactile } \\
\text { First } \\
\text { (Serrated } \\
\text { Edges) }\end{array}$ & $\begin{array}{c}\text { Visual } \\
\text { Second } \\
\text { (Size) }\end{array}$ & $\begin{array}{c}\text { Visual } \\
\text { First } \\
\text { (Size) }\end{array}$ & $\begin{array}{c}\text { Tactile } \\
\text { Second } \\
\text { (Serrated } \\
\text { Edges) }\end{array}$ \\
\hline $\begin{array}{l}\text { Mean Errors } \\
\begin{array}{l}\text { Mean Time to } \\
\text { Solution (Min) }\end{array}\end{array}$ & 13.54 & $\mathbf{8 . 3 6}$ & 22.00 & 21.36 \\
\hline
\end{tabular}

dimension accompanied by four irrelevant dimensions. The relevant dimension for the tactile problem was edges (smooth-serrated) and for visual, size (large-small).

The S's task in solving a two-choice concept identification problem was to categorize a series of geometric figures in accordance with one relevant binary stimulus dimension. For instance, where texture of the object was the relevant dimension, if $S$ pushed Button A when all objects were smooth and Button $B$ when rough, he would be correct. However, if Ss responded to the irrelevant dimensions (e.g., thickness: thin or thick), then Ss would be correct only at the chance level.

The tactile and visual stimuli were presented automatically and were S-paced. The visual stimuli were geometric figures and were varied along the following dimensions: size (large or small); horizontal position (left or right of screen); orientation (upright or tilted); number ( 1 or 2 ); and shape (square or triangle). On the tactile task the dimensions were: edges (serrated-smooth); dot or no dot on object; weight (heavy, i.e., $131.6 \mathrm{~g}$, or light, i.e., $65.8 \mathrm{~g}$ ); texture of object surface (smooth-rough); and shape (square or triangle). Ss' response panel for the visual and tactile tasks contained two response buttons labeled $A$ or $B$ and two amber feedback lights located just above the response buttons. The response of each $S$ automatically caused a light to be lit on his panel, indicating the correct response. A preplanned program of binary coding provided correct response information. On the visual task, photocells identified the correct response from the projector light sensed through the openings of the film on a $35-\mathrm{mm}$ slide. The visual stimuli were projected on a $6 \times 10 \mathrm{in}$. screen by a Sawyer $35-\mathrm{mm}$ slide projector. On the tactile task, binary coding was accomplished on a film strip using a film punch. The tactile stimuli were presented to the $S$ via a Davis universal feeder capable of holding and rotating, in sequence, the plastic objects. A black vinyl shield with two slits on each end in front of the console enabled Ss to insert both hands and feel the plastic object when it dropped into his hands from a delivery slot via a chute. The black shield prevented Ss from viewing the objects. When the $S$ made a decision on his response panel, he returned the plastic object into a second slot above the delivery slot, and it automatically returned to its assigned position in the dispenser.

All timing operations were programmed. A typical operation consisted of four automatically controlled time periods, i.e., a stimulus period, feedback delay, feedback duration, and postfeedback duration. The postfeedback interval was $2 \mathrm{sec}$, feedback duration was $2 \mathrm{sec}$, and feedback delay, 2 sec. Response latency was measured from time of onset of stimuli to buttonpress. In the visual task it was slide onset, and in the tactile, timing began when the objects dropped in S's hands. A pilot study resulted in a correction for latency for both tactile and visual tasks. It took $1 \mathrm{sec}$ for the object to be dispensed and $1.5 \mathrm{sec}$ for Ss to take their hands out of the shielding to buttonpress, totaling $2.5 \mathrm{sec}$. For the visual task, Ss took .5 sec to buttonpress. For data analysis, $2.5 \mathrm{sec}$ were subtracted from each trial in the tactile task and .5 sec for the visual.

A 12-digit BRS printout counter recorded errors and latency of each respone, and a digital decimal counter recorded time to solution.

After Ss were seated in front of the visual or tactile console in a soundproof room, they were given instructions concerning the tasks, significance of the response keys, and feedback lights. Criterion to solution was 16 consecutive correct responses. If criterion was not reached, then Ss were given a maximum of $20 \mathrm{~min}$ to reach solution.

\section{RESULTS AND DISCUSSION}

The main dependent variables were errors, time in minutes to criterion, and latency of response in seconds.

Error and time scores yielded essentially the same results. There were no significant differences between visual and tactile concept findings were consistent with those in a previous experiment where stimuli learning in errors or time. These were presented manually (Wolfang, 1969). The main effect of order $(\mathrm{F}=3.53, \quad \mathrm{~d} f=20, \quad \mathrm{p}<.10)$ approached significance, with $S$ s making twice as many enors with the tactile-visual combination $(\overline{\mathrm{X}}=21.68)$ than with the visual-tactile combination $(\vec{X}=10.96)$. Looking at Table 1 , the findings related to order of presentation suggest a trend in that Ss without prior tactile experience make three times as many errors and take almost twice as much time to reach solution in visual concept identification. A plausible reason for tactile experience's facilitating visual concept identification would be that Ss approaching the tactile task first became more involved and sensitized to the conceptual task by actively handling the tactile objects and came in direct contact with the relevant information. In contrast, in visual concept identification $\mathrm{Ss}$ are more passive in looking at the stimuli flashed on the screen.

\section{Response Latency}

Response latency was calculated only for presolution trials, i.e., up to when the last error was made, because some Ss solved the problem quickly and it was felt that decision time would reflect postsolution latency rather than latency associated with decision making.

Results showed that response latency was significantly longer in tactile concept identification $(\overline{\mathrm{X}}=6.18 \mathrm{sec})$ than visual $(\bar{X}=2.21 \mathrm{sec})$, that is, Ss took three times as long to classify each of the tactile objects than the visual $(\mathrm{F}=38.27, \mathrm{df}=20, \mathrm{p}<.001)$. This suggests that the eyes are quicker than the hands in scanning and identifying relevant information. This is not surprising when considering that we are taught to rely more on the visual sense and have more practice using it in decision making than the tactile sense.

In considering future experiments, one possible extension of the present study where results were based on an adult population would be to explore developmental differences in visual-tactile concept identification.

\section{REFERENCES}

BULGARELLA，R，G，\& ARCHER，E，J. Concept identification of auditory stimuli as a function of amount of relevant and irrelevant information. Journal of Experimental Psychology, 1962, 63, 254-257.

HALL, E. T. The hidden dimension. Garden City, N.Y: Doubleday, 1966.

HAYGOOD, D. H. Audio-visual concept formation. Journal of Educational Psychology, 1965, 56, 126-132.

LORDAHL, D. S. Concept identification using simultaneous auditory and visual signals. Journal of Experimental Psychology, 1961, 62, 283-290.

WOLFGANG, A. A comparison of tactile and visual concept learning. Psychonomic Science, 1969, 14, 175-176. 